\title{
Urban heat island modelling of a tropical city: case of Kuala Lumpur
}

\author{
Kai Wang ${ }^{1}$, Yasemin D. Aktas ${ }^{1 *} \mathbb{D}$, Jenny Stocker ${ }^{2}$, David Carruthers ${ }^{2}$, Julian Hunt ${ }^{3}$ and Liora Malki-Epshtein ${ }^{1}$
}

\begin{abstract}
The steep increase in urban populations results in the spatial extent of cities expanding both horizontally and vertically. The climatic response of urban areas differs greatly to rural areas exposed to the same environmental conditions, with urban temperatures generally being higher, particularly in the late afternoon and evening. Coupled with the upward trend in global temperatures, urban heating can be classified as an atmospheric hazard that affects a high proportion of the population in some countries, which needs to be addressed through local and national government planning strategies. This study presents preliminary findings from a city scale urban climate model developed using the fast climate modelling tool ADMS-Urban for the city of Kuala Lumpur, Malaysia, which is known to suffer from substantial urban heating, and discusses the extent and intensity of the urban heat island in light of existing literature based on field measurements. The model has been configured to use surface characteristic data derived from land-use data as input, and through comparison with temperature variations derived from satellite imagery, the model is seen to clearly capture the spatial variation of temperature over the domain. The urban heat island intensities predicted by the model are comparable to the values reported in literature. This study also demonstrates the strong relationship between temperatures and wind speed, which is generally much lower in tropical Kuala Lumpur compared to mid-latitudes, and the urban heat island intensity and nocturnal cooling. The future modelling studies should account for anthropogenic heating, for instance, from air conditioning units and traffic, which are important sources of heat in tropical areas, and expand more on building materials and morphology for a thorough appraisal of urban heating in Kuala Lumpur.
\end{abstract}

Keywords: Urban heat island, Land use, Urban climate modelling, ADMS-Urban

\section{Introduction}

Mega-urban areas in Asia are known to suffer from significant urban heating (Estoque et al. 2017; Hunt et al. 2018) with important implications on human health and wellbeing (O'Neill and Ebi 2009; Hajat et al. 2014), and Greater Kuala Lumpur is not an exception to this with its population expected to exceed 10 million by 2020 (PEMANDU 2014). Kuala Lumpur grew considerably in terms of size and population during the last 50 years with a rate of urbanisation among the highest in Southeast Asia (Yuen and Kong 2009), which has led to significant changes in the land use/land cover of the area and to the

\footnotetext{
*Correspondence: y.aktas@ucl.ac.uk

${ }^{1}$ Epicentre Research Group, UCL Department of Civil, Environmental and Geomatic Engineering, Gower Street, London WC1E 6BT, UK Full list of author information is available at the end of the article
}

disappearance of a clear boundary between the Petaling District and Federal Territory. The sharp increase in the number of motor vehicles in the resulting Klang Valley conurbation has resulted in a new central area circulation plan and a number of road projects. Land-use and land-cover changes combined with other contributing anthropogenic factors relating to the urbanisation and conurbation processes (traffic and waste heat from air conditioning systems, population increases) have modified the energy balance and induced spatiotemporal changes of urban climate in this area (Morris et al. 2017a).

The urban heat island (UHI) is a phenomenon where urban air temperatures are higher than the surrounding rural areas primarily as a result of the high thermal capacity of building materials, reduced latent heat flux relating to increased surface water drainage, increased 
anthropogenic heat and fewer open/green spaces in cities (Gago et al. 2013). UHI phenomenon has been widely studied as the major indicator of the impact of urban settings on local climate. Further, although there are fewer studies focussing on (sub)tropical regions than on midlatitude western urban areas (Roth 2007; Stewart 2011), there is a relatively well-developed literature on urban heating in Malaysia, particularly in Kuala Lumpur. These studies began in the early 1970 s by Sham Sani who, in more than two decades, showed the exacerbation of urban heating within Kuala Lumpur in relation to the increasing size of the city, changes in the cityscape (for instance, sea breeze obstruction by tall structures) and worsening in the anthropogenic factors (e.g. Sani 1972, 1984, 1990/91). More recently, studies have used different approaches, including surface energy balance modelling (e.g. Tso 1996; Tso and Chan 1990), satellite images and remote sensing (e.g. Ahmad and Hashim 2007; Yusuf et al. 2014), weather station and temperature sensor field monitoring (e.g. Sani 1972, 1984; Azid et al. 2015; Elsayed 2006, 2012a, b, c, d; Ahmad et al. 2010), as well as numerical modelling (e.g. Morris et al. 2017a, b; Ooi et al. 2017a) to evaluate the urban heat island around Kuala Lumpur. These studies reached a general consensus: (1) the urban heat island intensity (UHII) is continually increasing, with estimates within the last decade varying between $4.2{ }^{\circ} \mathrm{C}$ (Morris et al. 2017a) and $9.5^{\circ} \mathrm{C}$ (Ahmad et al. 2010); (2) the UHII is higher on the weekdays, highlighting the contribution of traffic-induced heating (Elsayed 2012a, b, c); (3) urban cool islands (for instance, in the vicinity of Lake Garden Park, or within older and leafier districts such as Kampung Baru; Sani 1972, 1984) are reducing in size and in some cases disappearing altogether, primarily due to heavy traffic in and surrounding these areas (Elsayed 2012a, b; cf. Azid et al. 2015) and (4) the warmest core of the city is shifting from around Chow Kit to the commercial district Puduraya, presumably due to the development of the Pudu Sentral Bus Terminal (Elsayed 2012a, c; cf. Sani 1984). In addition to various anthropogenic factors, the land-use/landcover changes, including the increase in built-up areas and reduction in green areas, have been identified as the primary drivers for the urban heat island in Greater Kuala Lumpur (Ramakreshnan et al. 2018). All these studies are in broad agreement that there is an increasing urban heating problem due to the urban development in Kuala Lumpur.

Kuala Lumpur $\left(3^{\circ} 09^{\prime} 35^{\prime \prime} \mathrm{N} 101^{\circ} 42^{\prime} 00^{\prime \prime} \mathrm{E}\right)$ is located in the tropics, and has two distinct monsoon seasons, i.e. the relatively drier Southwest Monsoon from May to September, and the rainy Northeast Monsoon from November to March (Ooi et al. 2017b). On course to be a world class city, Kuala Lumpur will continue its development in the next decade. Thus, it is of great importance to understand how different land-uses and land-covers impact its urban climate. A fast and reliable modelling tool suitable for the tropics is essential to help us predict future urban temperatures and to provide guidance for scientific and sustainable urban planning. In this study, the city scale urban climate modelling of Kuala Lumpur was undertaken by customising a fast local urban climate modelling tool, ADMS-Urban. Such fast, local-scale modelling tools have been widely used in the last decades to calculate temperature perturbations in mid-latitudes from city to neighbourhood/street level with the aim of studying the extent and spatiotemporal variation of UHI to help identify risk factors within a given urban context and to test the effectiveness of possible land-use change or mitigation scenarios (e.g. Jacobson and ten Hoeve 2012; Virk et al. 2014, 2015), but their customisation for use to model (sub)tropical cities has not been achieved.

In this study, the preliminary findings from this city scale climate model of Greater Kuala Lumpur are presented in conjunction with satellite images to discuss the model setup and input, as well as the factors that govern the urban heating phenomenon in a tropical Asian city in comparison to mid-latitude cities.

\section{Data and methods}

Details of model inputs and configuration are given in the following sections.

\section{City scale urban climate modelling of Greater Kuala Lumpur by ADMS-Urban}

ADMS-Urban (previously ADMS-T\&H) has been widely used to study the urban climates on a city scale (e.g. Maggiotto et al. 2014; Mavrogianni et al. 2011) as well as on a neighbourhood/street scale (e.g. Hamilton et al. 2014; Aktas et al. 2017). In this study, city scale urban climate modelling of Greater Kuala Lumpur has been performed.

ADMS-Urban uses meteorological input to calculate heat flux parameters using the following surface energy balance equation:

$$
Q^{*}+Q_{\mathrm{F}}=G+H+\mathrm{LE},
$$

where $Q^{*}$ is the net radiation, $Q_{\mathrm{F}}$ is the anthropogenic heat, $G$ is the heat storage due to the conduction of heat to the surface, $H$ is the sensible heat transfer and LE is the latent heat transfer.

Using the weather data from rural area as input, ADMS-Urban can model the urban climate by accounting for the perturbations of heat from net radiation, anthropogenic heat, heat storage, sensible and latent heat transfer. The perturbations of heat are calculated based on the differences in thermophysical properties between the modelled area and input area. Thus, detailed land-use 
data are essential for ADMS-Urban modelling (CERC 2017). The modelling work reported here used input parameters derived from a variety of sources. Kuala Lumpur City Hall (DBKL) supplied detailed land-use data defined by function (commercial, residential, etc.). The land-cover data, i.e. physical properties of the surfaces (building materials, wooded areas, urban parks, etc.), were not available. U.S. Geological Survey (USGS) 30-m global land-cover data (https://landcover.usgs.gov/glc/) were used to refine some of the land-use categories, specifically green space and open areas. Land-use data thus collated for the entire Greater Kuala Lumpur are shown in Fig. 1.
All land-use categories were gridded to $50 \mathrm{~m}$ prior to assigning the physical properties listed in Table 1: the albedo, thermal admittance and surface resistance to evaporation parameters. The physical properties were then resampled at a 100 -m grid resolution. Land-use data outside Kuala Lumpur were resampled at a 500-m resolution based on the European Space Agency, Global Land Cover map from 2015 (https://www.esa-landc over-cci.org/), which has a resolution of $300 \mathrm{~m}$, and physical parameters were assigned (Table 1). The physical parameters required as input for the ADMS-Urban model relate to the capacity of a surface to reflect, absorb and reradiate heat, namely albedo, thermal admittance and surface resistance to evaporation; these

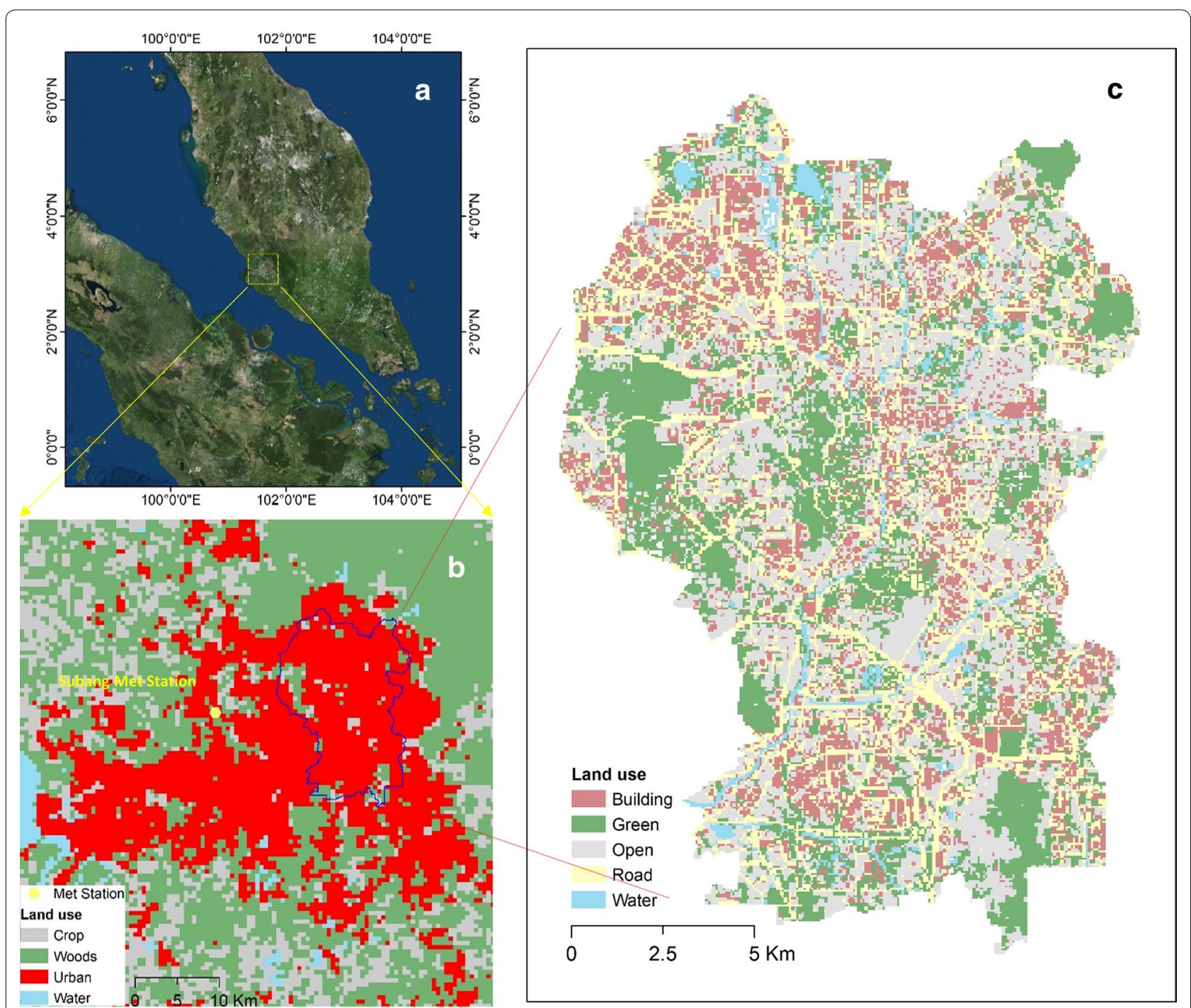

Fig. 1 a Malay Peninsula (ArcMap 10.5 base Map), b Greater Kuala Lumpur land-use categorisation and c Kuala Lumpur city land-use categorisation in further detail 
Table 1 Land-use categories and defined physical properties for Kuala Lumpur (KL) and Greater Kuala Lumpur (GKL)

\begin{tabular}{|c|c|c|c|c|}
\hline & Land-use categories & Albedo (-) & $\begin{array}{l}\text { Thermal admittance } \\
\left(\mathrm{J} \mathrm{m}^{-2} \mathrm{~s}^{-1 / 2} \mathrm{~K}^{-1}\right)\end{array}$ & $\begin{array}{l}\text { Surface resistance } \\
\text { to evaporation } \\
\left(\mathrm{s} \mathrm{m}^{-1}\right)\end{array}$ \\
\hline \multirow[t]{5}{*}{$\mathrm{KL}$} & Building & 0.12 & 1505 & 250 \\
\hline & Road & 0.08 & 1205 & 250 \\
\hline & Open & 0.18 & 600 & 250 \\
\hline & Green & 0.2 & 300 & 37 \\
\hline & Water & 0.08 & 1545 & 0 \\
\hline \multirow[t]{4}{*}{ GKL } & Urban & 0.14 & 882 & 194 \\
\hline & Cropland & 0.157 & 600 & 70 \\
\hline & Woods & 0.15 & 300 & 37 \\
\hline & Water & 0.08 & 1545 & 0 \\
\hline
\end{tabular}

values were chosen from land-use information collated for the entire domain. The land-use categories for Kuala Lumpur were chosen in line with the data made available by DBKL. For outside the city boundaries, on the other hand, a relatively lower resolution land-use categorisation was used due to data limitations. The physical parameters for category urban, on the other hand, were assigned a mean value obtained for Kuala Lumpur city (Table 1, derived from Aktas et al. 2017; CERC 2017).

As such, a relatively rough set of land-use categories was used for both KL and GKL: all buildings and nonspecific open areas (which are not labelled as part of parks or woods) were assumed to be made of concrete, and values assigned to green areas did not account for different vegetation types (an in-depth study demonstrating the impact of using more refined land-use and land-cover classifications is given in Aktas et al. (2017)). The surface resistance to evaporation value $\left(r_{\mathrm{s}}\right)$ for green areas and woods was calculated as $37 \mathrm{~s} / \mathrm{m}$ based on Eq. (1) given below (Fen Shu 1982; Tran et al. 2015).

$$
r_{\mathrm{s}}=3.5\left(\frac{\theta_{\mathrm{sat}}}{\theta}\right)^{2.3}+33.5
$$

where $\theta$ and $\theta_{\text {sat }}$ are volumetric water content in the 0-5 mm soil layer and saturated water content of the soil, respectively, which were assumed to be equal to each other to reflect the high moisture content of soil due to frequent and intense precipitation in tropical areas. For this study, the day selected for analysis was 30 May 2015. This was mainly because satellite imagery with minimal cloud cover was available for this day (see "Landsat 8 images" section). The assumptions made in the calculation of the surface resistance to evaporation are in broad agreement with this selected day selected for analysis, which, despite occurring during the dry South West
Monsoon season (boreal summer monsoon between May and September; see Ooi et al. 2017b), followed a precipitation incident the previous evening. This particular day was chosen for analysis because of the availability of satellite imagery with minimum cloud cover.

In addition to the mentioned physical input parameters and meteorological data, the morphological input parameter, normalised building volume (NBV), was derived using the 3D buildings data, also obtained from the DBKL, and used for the model setup to calculate spatial and temporal temperature perturbations over the model domain. The surface roughness length, which is another morphological parameter, was assigned empirical values based on the land-use categories chosen for GKL: 0.5 for urban, 0.5 for woods, 0.1 for cropland and 0.001 for water surfaces. Each model was run over 2 days, and the latter 24-h outputs of air temperatures at $3 \mathrm{~m}$ from the ground were used for analysis to allow the model to account for the diurnal cycle of heat absorption and release.

\section{Landsat 8 images}

Due to data availability limitations at this stage, we are unable to obtain data from the meteorological stations inside the city to validate our model. In order to evaluate the city scale model of Greater Kuala Lumpur, the Landsat 8 Operational Land Imager (OLI)/Thermal Infrared Sensor (TIRS) Collection 1 Level-1 data were therefore used to derive the ground surface temperature values. Landsat 8 OLI sensor collects data for nine shortwave spectral bands with $30 \mathrm{~m}$ spatial resolution for eight bands in the visible, near-infrared and shortwave infrared regions and the panchromatic band at $15 \mathrm{~m}$ spatial resolution. The TIRS consists of two TIR bands, i.e. TIRS-1 Band 10 from 10.6 to $11.19 \mu \mathrm{m}$ and TIRS-2 Band 11 from 11.50 to $12.51 \mu \mathrm{m}$, both of which collect TIR radiance data at $100 \mathrm{~m}$ spatial resolution. As mentioned above, the satellite image obtained from the U.S Geological Survey 
(https://landsat.usgs.gov/) for 30 May 2015, when the cloud cover was less than $15 \%$, was used in this study.

The Single-Channel Algorithm that developed by Jiménez-Muñoz et al. (2009) was used here to retrieve the land surface temperatures (LSTs) by means of the TIRS-1 band data (Jiménez-Muñoz et al. 2014).

In this study, as the water vapour content is not available, the atmospheric function parameters were obtained from the Atmospheric Correction Parameter Calculator (Barsi et al. 2003, 2005).

Another parameter required to retrieve land surface temperatures (LSTs) is the land surface emissivity. In this study, the land surface emissivity was estimated using the Normalised Difference Vegetation Index (NDVI) Thresholds Method (Sobrino et al. 2008; Jiménez-Muñoz et al. 2009). Negative NDVI values were assumed to be water surfaces, where the assigned emissivity was 0.995 . The calculated NDVI and the derived land surface emissivity of the study area are shown in Fig. 2.

\section{Results}

\section{Comparison of the spatial distribution between ADMS-Urban output and land surface temperatures}

A satellite image of Greater Kuala Lumpur was generated for 30 May 2015 at 11:27 (Malaysian local time). ADMSUrban predicts hourly average temperatures and uses the hour-ending convention, so output from 12:00 noon on the same day was used for a comparison of the spatial variation of temperatures at $3 \mathrm{~m}$ height above ground over the Greater Kuala Lumpur area (Fig. 3). At this time, the air temperature at Subang meteorological station (shown in yellow in Fig. 1b) was $33.4{ }^{\circ} \mathrm{C}$ and the wind speed was $3.7 \mathrm{~m} / \mathrm{s}$ from southeast direction $\left(120^{\circ}\right)$. The model predictions of aboveground air temperatures and surface temperature values derived from the satellite data cannot be directly compared, as the ranges of surface temperatures are always larger than the air temperatures; however, it is shown that the ADMS-Urban gives a good prediction for the spatial pattern of temperature perturbations over the modelling domain, characterised by different land uses. Both model outputs and satellite image show the contrasting temperature distribution between green areas and built-up areas over Greater Kuala Lumpur. The model output had captured the lowest temperature values in the wooded areas East of Kuala Lumpur city beyond Ampang Jaya. Such contrasting temperature distributions on different land uses are also shown by the ADMS-Urban output and LSTs in Kuala Lumpur city (Fig. 4). The model also indicates higher temperatures in the northern part of Kuala Lumpur (e.g. Kepong and Sentul), also shown in the LSTs.

In terms of resolution, clearly the satellite images (Figs. $3 \mathrm{~b}$ and $4 \mathrm{~b}$ ) have a much finer resolution than the model. The model is restricted by the calculation grid resolution, which is relatively coarse (approximately $115 \mathrm{~m}$ ); refining the land-use inputs to the model, for instance, distinguishing between open green and wooded
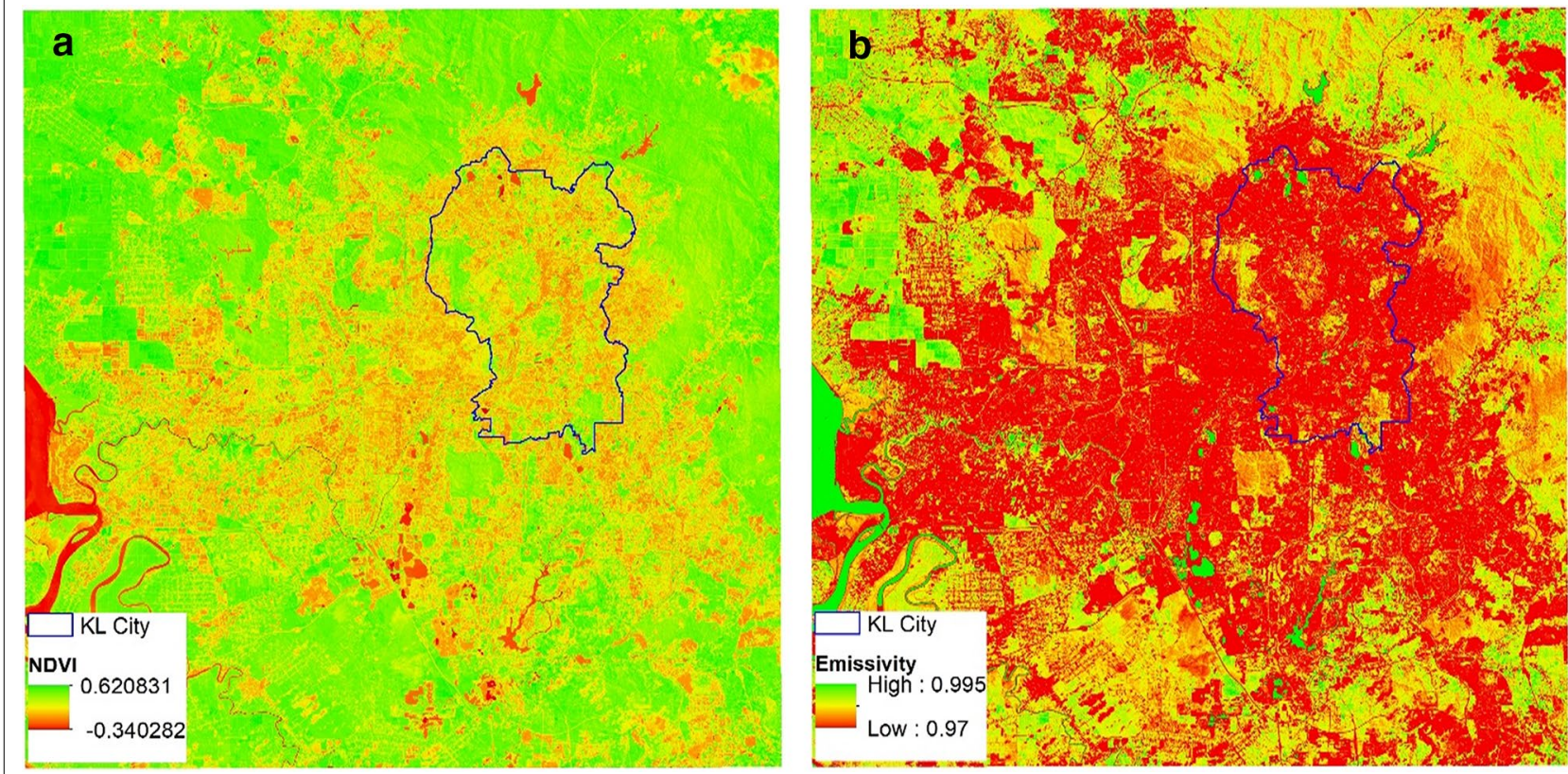

Fig. 2 a Derived NDVI and $\mathbf{b}$ land surface emissivity of the study area 


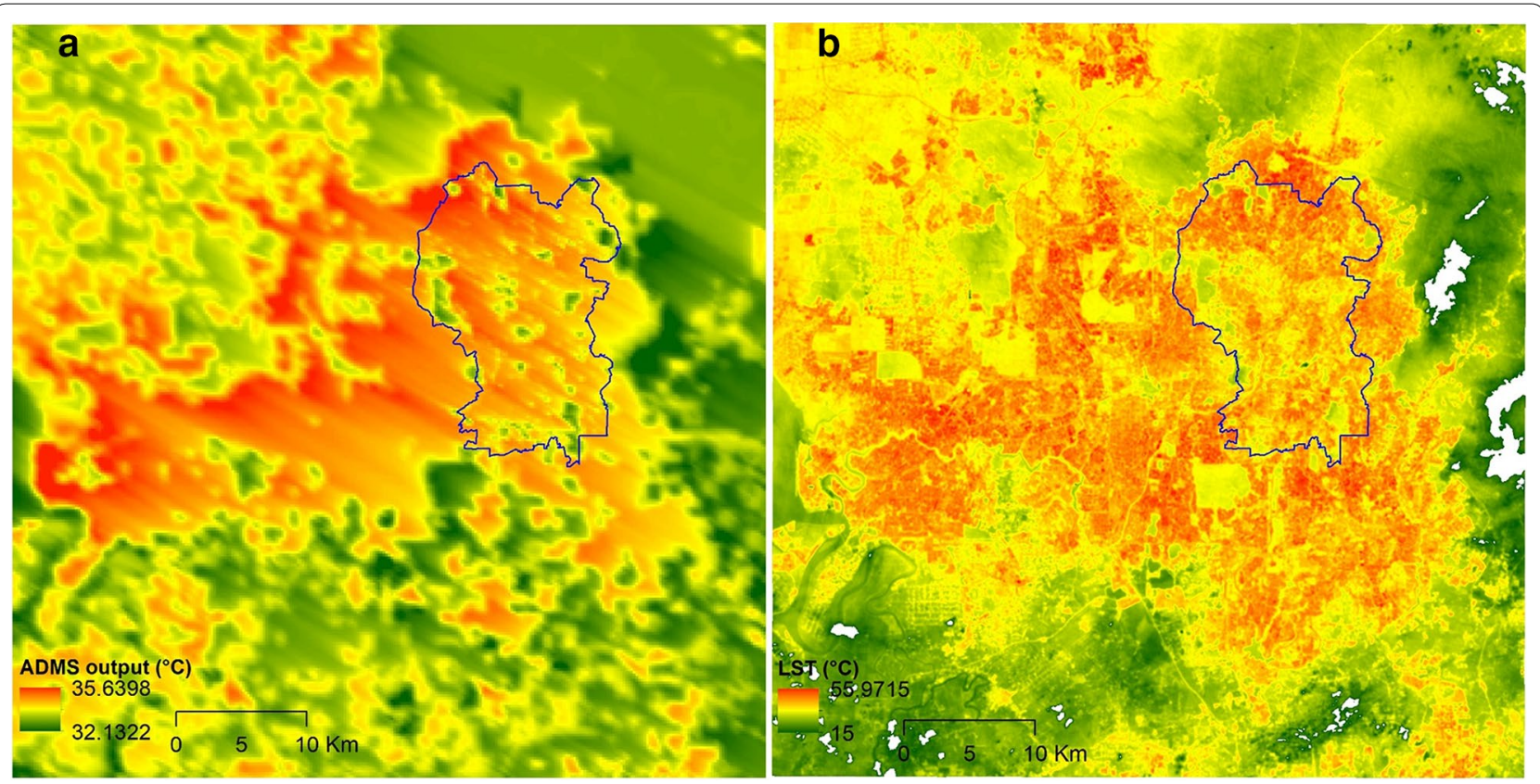

Fig. 3 a ADMS-Urban modelled air temperatures at $3 \mathrm{~m}$ above ground (12:00 noon) and $\mathbf{b}$ derived LSTs (11:27 a.m.) for the Greater Kuala Lumpur, blanks are areas with derived LSTs lower than $15^{\circ} \mathrm{C}$ due to cloud cover

areas and accounting for the variation in thermal capacity of the buildings, as in Aktas et al. (2017), would also help improve the model resolution if more detailed landcover data were available for the full domain. Although sub-domains that use 'urban' input meteorological conditions may be considered at higher resolution, for this city scale study it was necessary to include the full domain in order for the model to account for the generation of the full Greater Kuala Lumpur UHI. To enhance the comparability of satellite imagery and model output, the LSTs were resampled to the same resolution as ADMS outputs (Fig. 5). The Pearson correlation coefficient between LST and ADMS outputs was calculated as $0.43(p<0.01)$, suggesting a moderate positive correlation. However, the satellite image indicates a stronger UHII in the southeast of the domain in Fig. 3 compared to the model-a possible explanation for this may be that the model over-predicts the influence of advection of heat from the southeast to the northwest.

\section{Modelled air temperature values in different land-use areas}

Because UHI is highest in late afternoon/evening, the model output obtained for 6 p.m. was used to examine the UHII. The results show that over the entire model domain, the calculated temperature values range between 29.3 and $37.3{ }^{\circ} \mathrm{C}$, which indicates a UHII of around $8{ }^{\circ} \mathrm{C}$ (Fig. 6), which is comparable to the values reported in literature. It should be borne in mind, however, that the model currently does not account for the anthropogenic heating-which, reportedly, can be as high as $1.5^{\circ} \mathrm{C}$ in various Asian cities of a comparable size and intensity ( $\mathrm{Li}$ et al. 2015; Wang et al. 2018; Ichinose et al. 1999), overall putting the model predictions of UHII for Kuala Lumpur in line with the higher end of previous predictions, i.e. $9.5^{\circ} \mathrm{C}$ by Ahmad et al. (2010).

In order to further discuss the difference in temperature variations over different land-use areas, the diurnal variations in the modelled air temperatures of green and built-up areas have been studied. Modelled temperatures at Perdana Botanical Garden (Tasik Perdana) and the City Centre (Fig. 7) were analysed for the 30th of May 2015. The modelled air temperatures at $3 \mathrm{~m}$ above ground (Fig. 8a) indicate that the modelled air temperatures in the City Centre are up to $1.4{ }^{\circ} \mathrm{C}$ higher than that those in Tasik Perdana; this maximum temperature difference appears at 18:00 and coincides with a sharp drop of wind speed around that time (Fig. 8b), which highlights the inverse relationship between urban temperatures and wind speed values.

\section{Impact of wind speed}

To further study the impact of wind speed on the urban heating, a reduced wind speed case was evaluated, where the input wind speed values used for the base case analyses were halved, with all other input parameters 

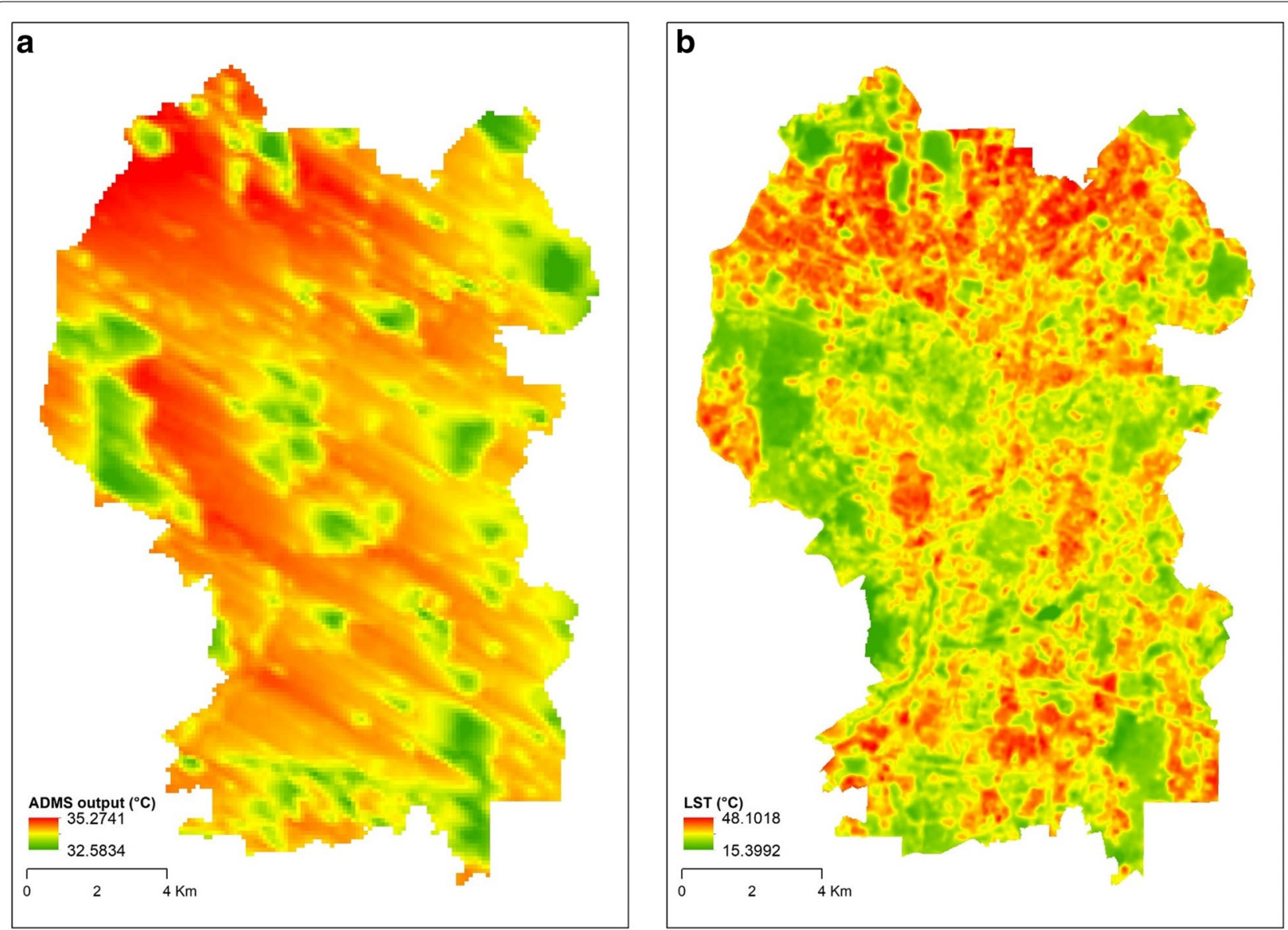

Fig. 4 a ADMS-Urban modelled air temperatures (12:00 noon) and b derived LSTs (11:27 a.m.) for Kuala Lumpur city

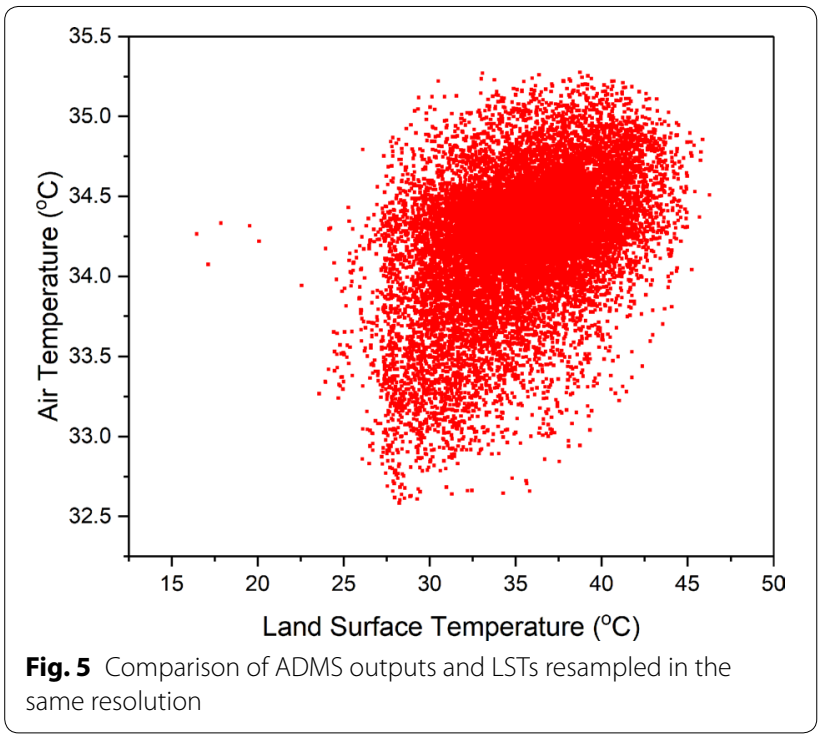

unchanged. The differences in the temperature predictions and the input wind speed from these two cases are shown in Fig. 9. Data from 8 a.m. to midnight are compared here, as the ambient wind speed at 1 a.m. and 5 a.m. to 7 a.m. was all lower than the critical minimum wind speed value that can be defined in ADMS-Urban modelling. The temperature differences between the built-up and green areas are always higher in the reduced wind case (up to more than $1{ }^{\circ} \mathrm{C}$ ), except for when there is not wind at all. In reduced wind speed case, the temperature difference (built-up minus green) is much larger, suggesting that the wind speed can largely affect the nocturnal cooling. However, at daytime, the change in the temperature difference due to wind speed is very small. 


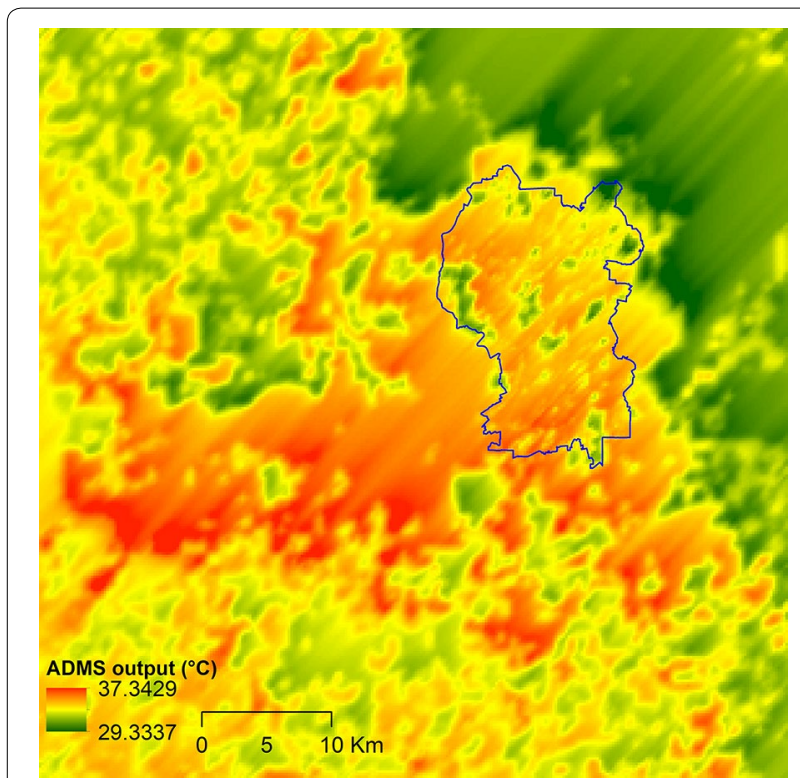

Fig. 6 Temperature distribution over the modelling domain for 18:00, 30 May 2015

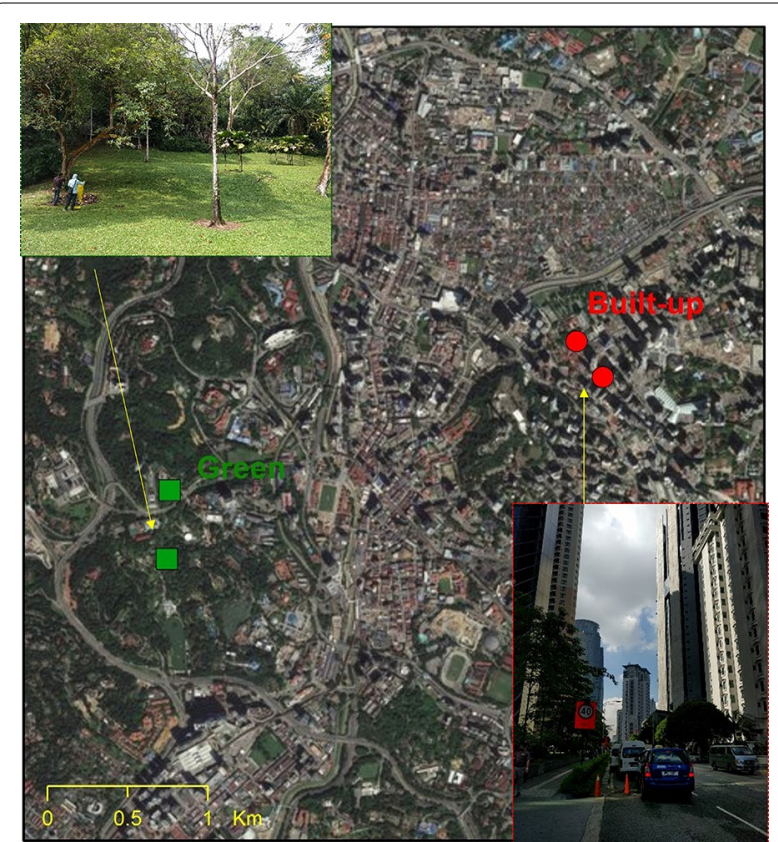

Fig. 7 Locations and images of the selected built-up area locations in City Centre (red dots) and green area in Tasik Perdana (green dots) (ArcMap 10.5 Base Map)

\section{Discussion, conclusions and future work}

ADMS-Urban, like many other fast local urban climate modelling tools, has been thus far used and validated mostly for mid-latitude western cities. In this paper, the ADMS-Urban was used to model the urban climate of tropical Greater Kuala Lumpur. The surface air temperatures are determined by the surface energy balance equation; however, the energy portioning and heat transfer processes in the tropical areas differ from the midlatitudes (Roth 2007) due to climatic, anthropogenic and morphological factors. Climatic factors include both poor dispersion due to low wind speeds, and the larger amount of latent heat due to more frequent and intense precipitation. Kuala Lumpur also experiences increased anthropogenic heat due to larger traffic loads and air conditioning use, which generate extra challenges in the modelling of this and similar tropical urban climates.

Differences in urban morphologies have strong impact on the radiation, heat transfer and aerodynamics, which are the key factors that govern urban climates. The urban morphology of typical Asian cities, including Kuala Lumpur, is quite different due to higher density of high-rise buildings to that of typical mid-latitude, European cities for which ADMS has been previously validated. For example, the normalised building volume (NBV) calculated for $500 \mathrm{~m}$ resolution in the Kuala Lumpur city centre is close to $60 \mathrm{~m}$, which is over five times as high as maximum NBVs in London. Further, it is normally possible to calculate surface roughness values using the $3 \mathrm{D}$ buildings data, if available, based on the expression developed by MacDonald et al. (1998); however, due to comparatively very high-rise-high-density nature of KL, the use of this equation results in unrealistically high predictions. Therefore, we find that low-resolution generic surface roughness values were best suited for this study.

Further, the wind speed values in tropical areas are almost always lower, resulting in poor dispersion of heat and air pollutants in tropical cities. Poor dispersion is further exacerbated in the case of Kuala Lumpur, as it is located inside the Klang valley (Sani 1990/91). In addition, the high moisture content in green areas combined with strong solar radiation leads to large latent heat fluxes in tropical cities, making the flux ratios different from the majority of mid-latitude climates.

This first attempt at using ADMS-Urban to model the local climate in Greater Kuala Lumpur results in good agreement between the spatial distribution of temperatures predicted by the model and derived from satellite imagery data. However, the range of predicted LSTs is quite high (over $40{ }^{\circ} \mathrm{C}$ ) and it is likely that a refinement in the methodology used to calculate these would make this temperature range narrower-specifically by obtaining accurate water vapour value, eliminating the impacts of clouds, applying a dark object subtraction correction and refining the emissivity parameters. The model can capture the temperature variations between built-up and green area, which shows the diurnal variation of urban heat island, and the impact of wind speed on the urban 

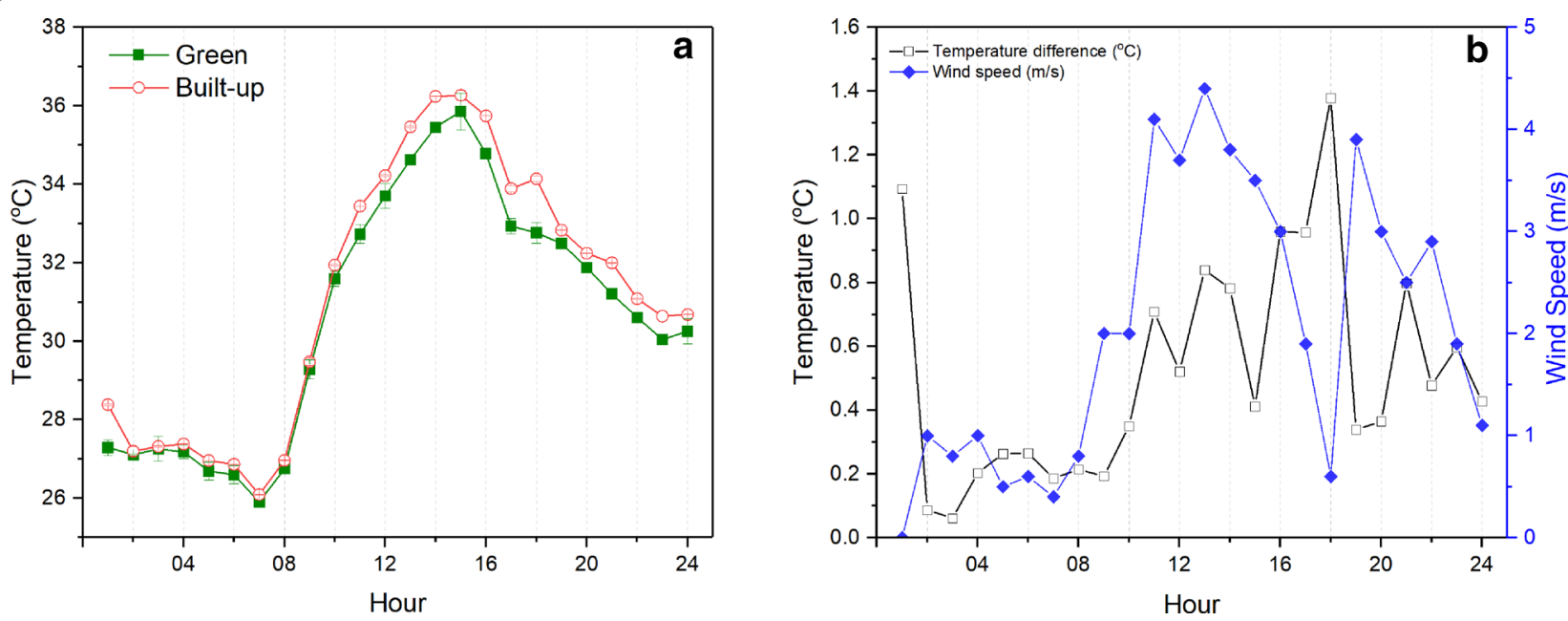

Fig. 8 a Diurnal variation of model output for air temperatures in green and two built-up locations (average of two locations of the same land-use category), $\mathbf{b}$ relationship between wind speed and temperature difference between built-up and green areas

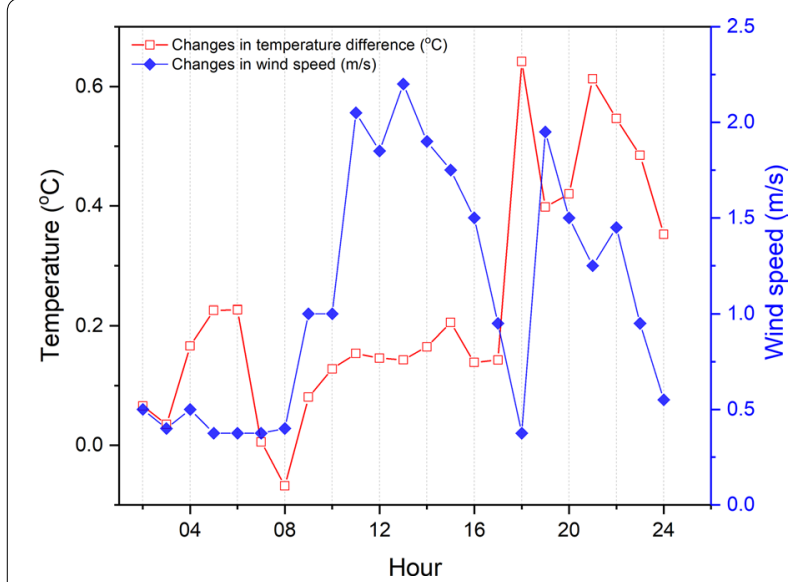

Fig. 9 Changes in the temperature difference (Built-up minus Green) and wind speed between reduced wind speed case and base case

heat island intensity. Our findings are in broad agreement with previous studies that suggested the inverse relationship between wind and urban heat island (e.g. Oke 1987; Arnfield 2003; Aktas et al. 2017). Our analysis of reduced wind speed case further indicates that the impact of wind speed on the urban temperatures differs in the daytime and nighttime. During the night, the wind speed appears to be an important factor for the nocturnal cooling process, resulting in a relatively lower nocturnal boundary layer, and impacting on the advection and convection heat transfer processes. The reduced wind speed values are more directly linked to a higher urban heating. During the day, however, the relationship between urban temperatures and wind speed is more complex, as the daytime climatic factors are also influenced by advection, convective heat transfer and evapotranspiration, among others. Further research on different components of energy balance fluxes is needed to distinguish such different impacts.

In this study, the predicted UHII is within the range of values reported by previous research. On the other hand, current ADMS-Urban city scale model did not fully take into account the anthropogenic heating, both from road emissions and air conditioning systems. Previous studies suggested that the larger UHII appeared in weekdays due to the contribution from the heavy traffic, and the waste heat from the air conditioning systems shall be considerably large in the warm seasons, e.g. the day the model was run for, 30th May. Such anthropogenic heating factors contribute significantly to the observed UHII and vary its spatial distribution. Future modelling, on both city and neighbourhood scale, will fully account for the impacts of anthropogenic heat. Importantly, due to the limitations in the data availability, we used the LSTs derived from a Landsat satellite image to validate our modelling. Thus, only one-day modelling results were analysed in this study. At this certain day, the cloud amount was low, increasing the solar radiation, leading to a larger UHII. Hourly data from other meteorological stations inside the city are essential to validate the performance of our model. Such validation will be conducted when such data are available. Future research will also further develop the land-use categories and develop neighbourhood scale models that better represent building morphology and construction materials. Both open green parks and wooded area are defined as "Green" in the current 
study. In the upcoming neighbourhood scale models, a more detailed land-use categorisation will be adopted, in order to distinguish bare soil and concrete surfaces, the grass lands and wooded lands and different buildings materials. For example, as a traditional timber housing area, Kampung Baru, had previously been identified as an urban cool island, but has now been reported to be disappearing due mostly to the anthropogenic heat from heavy traffic. A study of the characteristics of temperature variations within this area, accounting for the low-rise low-density nature of this neighbourhood built mostly in timber, can largely help distinguish the contribution and relative importance of buildings and anthropogenic heating to the urban climate. Future research will also use extensive near surface field measurements on a wide range of different land-use areas for further model validation. Heavy precipitation and different seasons will also be considered for future modelling, to understand how the tropical urban hydrological cycle alters the local climate.

\section{Abbreviations \\ DBKL: Kuala Lumpur City Hall; GKL: Greater Kuala Lumpur; KL: Kuala Lumpur; LST: land surface temperature; NBV: normalised building volume; NDVI: Normalised Difference Vegetation Index; OLI: Operational Land Imager; TIRS: Thermal Infrared Sensor; UHI: urban heat island; UHII: urban heat island inten- sity; USGS: U.S. Geological Survey}

\section{Authors' contributions}

$\mathrm{KW}, \mathrm{YDA}$ and JS conducted the research and drafted the manuscript. DC helped in modelling and data analysis. JH and LM-E helped to draft the manuscript with thorough discussions. All authors read and approved the final manuscript.

\section{Author details}

'Epicentre Research Group, UCL Department of Civil, Environmental and Geomatic Engineering, Gower Street, London WC1E 6BT, UK. ${ }^{2}$ Cambridge Environmental Research Consultants (CERC), 3 King's Parade, Cambridge CB2 1SJ, UK. ${ }^{3}$ UCL Department of Earth Sciences, Gower Street, London WC1E 6BT, UK.

\section{Acknowledgements}

This study was carried out as part of "Future Cities-Disaster Resilient Cities: Forecasting Local Level Climate Extremes and Physical Hazards for Kuala Lumpur", jointly funded by Innovate UK and EPSRC under the Malaysia-UK Research and Innovation Bridges Competition for Collaborative R\&D: DC and JS for InnovateUK Grant ref. 102718, JH for EPSRC Grant ref. EP/P015476/1, YDA, KW, LM-E for EPSRC Grant ref. EP/P015506/1. We are indebted to the Malaysian project leader Professor Joy Pereira. We are grateful to UKM's Dr. Lim ChounSian and Dr. Muhamad, and MetMalaysia's Dr. Muhammad Firdaus Ammar for the acquisition of land-use and meteorological data, and Prof Johnny Chan and Prof Jimmy Fung for organising and hosting the Urban Meteorology and Climate Conference in May 2017 in Hong Kong, which made this publication possible. Landsat 8 image is courtesy of the U.S. Geological Survey.

\section{Competing interests}

The authors declare that they have no competing interests.

\section{Availability of data and materials}

30-m land-cover data for KL city and Landsat 8 satellite image were obtained from USGS (https://www.usgs.gov/). 300-m Land Cover map for GKL was obtained from ESA Climate Change Initiative (https://www.esa-landcover-cci. org/). Data analysed in this study are available from the corresponding author (YDA) on reasonable request.
Consent for publication

Not applicable.

Ethics approval and consent to participate

Not applicable.

\section{Funding}

Funding information is provided in "Acknowledgements" section.

\section{Publisher's Note}

Springer Nature remains neutral with regard to jurisdictional claims in published maps and institutional affiliations.

Received: 21 March 2018 Accepted: 9 April 2019

Published online: 23 April 2019

\section{References}

Ahmad S, Hashim NM (2007) Effect of soil moisture on urban heat island occurrences: case of Selangor, Malaysia. Humanity Soc Sci J 2(2):132-138

Ahmad S, Hashim NM, Jani YM, Aiyub K, Mahmod MF (2010) The effects of different land uses on the temperature distribution in urban areas. SEAGA, Hanoi

Aktas YD, Stocker J, Carruthers D, Hunt J (2017) A sensitivity study relating to neighbourhood-scale fast local urban climate modelling within the built environment. Procedia Eng 198:589-599

Arnfield AJ (2003) Two decades of urban climate research: a review of turbulence, exchanges of energy and water, and the urban heat island. Int J Climatol 23:1-26

Azid S, Zaki SA, Razak KA (2015) Spatiotemporal analysis on the squatter development: a case study in Kampung Baru, Kuala Lumpur. In: International joint conference of Senvar-Inta-Avan, Johor. pp 45-52

Barsi JA, Barker J, Schott JR (2003) An atmospheric correction parameter calculator for a single thermal band earth-sensing instrument. In: IGARSS03. Centre de Congres Pierre Baudis, Toulouse, France

Barsi JA, Schott JR, Palluconi FD, Hook SJ (2005) Validation of a web-based atmospheric correction tool for single thermal band instruments. In: Earth observing systems X, Proc. SPIE, Vol 5882, San Diego, CA

CERC (2017) ADMS-urban urban air quality management system user guide. CERC, Cambridge

Elsayed IS (2006) The effects of urbanization of the intensity of the urban heat island: a case study on the city of Kuala Lumpur, Malaysia. Ph.D Thesis submitted to International Islamic University

Elsayed IS (2012a) Mitigation of the urban heat island of the city of Kuala Lumpur, Malaysia. Middle-East J Sci Res 11(11):1602-1613

Elsayed IS (2012b) A study on the urban heat island of the city of Kuala Lumpur, Malaysia. JKAU Metrol Environ Arid Land Agric Sci 23(2):121-134

Elsayed IS (2012c) The effects of traffic activity on the intensity of the urban heat island: a case study on the city of Kuala Lumpur. Sudan Eng Soc J 58(2):9-16

Elsayed IS (2012d) Effects of population density and land management on the intensity of urban heat islands: a case study on the city of Kuala Lumpur, Malaysia. In: Alam BM (ed) Application of geographic information systems. Intech, London, pp 267-282

Estoque RC, Murayama Y, Myint SW (2017) Effects of landscape composition and pattern on land surface temperature: an urban heat island study in the megacities of Southeast Asia. Sci Total Environ 577:349-359

Fen Shu S (1982) Moisture and heat transport in a soil layer forced by atmospheric conditions. Connecticut, M.sc thesis submitted to University of Connecticut

Gago EJ, Roldan J, Pacheco-Torres R, Ordóñez J (2013) The city and urban heat islands: a review of strategies to mitigate adverse effects. Renew Sustain Energy Rev 25:749-758

Hajat S, Vardoulakis S, Heaviside C, Eggen B (2014) Climate change effects on human health: projections of temperature-related mortality for the UK during the 2020s, 2050s and 2080s. J Epidemiol Community Health 68:641-648 
Hamilton I, Stocker J, Evans S, Davies M, Carruthers D (2014) The impact of the London Olympic Parkland on the urban heat island. J Build Perform Simul 7(2):119-132

Hunt JC, Aktas YD, Mahalov A, Moustaoui M, Salamanca F, Georgescu M (2018) Climate change and growing megacities: hazards and vulnerability. In: Proceedings of Institution of Civil Engineers —engineering sustainability, pp 314-326

Ichinose T, Shimodozono K, Hanaki K (1999) Impact of anthropogenic heat on urban climate in Tokyo. Atmos Environ 33(24-25):3897-3909

Jacobson MZ, ten Hoeve JE (2012) Effects of urban surfaces and white roofs on global and regional climate. J Clim 25:1028-1043

Jiménez-Muñoz JC, Cristóbal J, Sobrino JA, Sòria G, Ninyerola M, Pons X (2009) Revision of the single-channel algorithm for land surface temperature retrieval from Landsat thermal-infrared data. IEEE Trans Geosci Remote Sens 47(1):339-349

Jiménez-Muñoz JC, Sobrino JA, Skoković D, Mattar C, Cristóbal J (2014) Land surface temperature retrieval methods from Landsat- 8 thermal infrared sensor data. IEEE Geosci Remote Sens Lett 11(10):1840-1843

Li C, Cao Y, Zhang M, Wang J, Liu J, Shi H, Geng Y (2015) Hidden benefits of electric vehicles for addressing climate change. Sci Rep 5:9213

Macdonald RW, Griffiths RF, Hall DJ (1998) An improved method for the estimation of surface roughness of obstacle arrays. Atmos Environ 32(11):1857-1864

Maggiotto G, Buccolieri R, Santo MA, di Sabatino S, Leo LS (2014) Validation of temperature-perturbation and CFD-based modelling for the prediction of the thermal urban environment: the Lecce (IT) case study. Environ Model Softw 60:69-83

Mavrogianni A, Davies M, Batty M, Belcher SE, Bohnenstengel SI, Carruthers D et al (2011) The comfort, energy and health implications of London's urban heat island. Build Serv Eng Res Technol 32(1):35-52

Morris KI, Chan A, Morris KJ, Ooi MC, Oozeer MY, Abakr YA et al (2017a) Impact of urbanization level on the interactions of urban area, the urban climate, and human thermal comfort. Appl Geogr 79:50-72

Morris Kl, Chan A, Morris KJ, Ooi MC, Oozeer MY, Abakr YA et al (2017b) Urbanisation and urban climate of a tropical conurbation, Klang Valley, Malaysia. Urban Clim 19:54-71

Oke TR (1987) Boundary layer climates, 2nd edn. Routledge, New York

O'Neill MS, Ebi KL (2009) Temperature extremes and health: impacts of climate variability and change in the United States. J Occup Environ Med 51(1):13-25

Ooi MC, Chan A, Ashfold MJ, Morris Kl, Oozeer MY, Aekbal Salleh S (2017a) Numerical study on effect of urban heating on local climate during calm inter-mansoon period in greater Kuala Lumpur, Malaysia. Urban Clim 20:228-250

Ooi MC, Chan A, Subramaniam K, Morris Kl, Oozeer MY (2017b) Interaction of urban heating and local winds during the calm intermonsoon seasons in the tropics. J Geophys Res Atmos 122(21):11499-11523
PEMANDU (2014) Greater Kuala Lumpur/Kelang Valley: ETP annual report. PEMANDU, Kuala Lumpur

Ramakreshnan L, Aghamohammadi N, Fong CS, Ghaffarianhoseini A, Ghaffarianhoseini A, Wong LP, Suleiman NM (2018) A critical review of urban heat island phenomenon in the context of Greater Kuala Lumpur, Malaysia. Sustain Cities Soc 39:99-113

Roth M (2007) Review of urban climate research in (sub)tropical regions. Int J Climatol 27:1859-1873

Sani S (1972) Some aspects of urban micro-climate in Kuala Lumpur West Malaysia. Akademika 1:85-94

Sani S (1984) Urban development and changing patterns of night time temperatures in Kuala Lumpur-petaling Jaya area Malaysia. Jurnal Teknologi Bil 5:27-36

Sani S (1990/91) Urban climatology in Malaysia: an overview. Energy Build. 15-16:105-117

Sobrino JA-M, Sòria G, Romaguera M, Guanter L, Moreno J, Plaza A, Martínez P (2008) Land surface emissivity retrieval from different VNIR and TIR sensors. IEEE Trans Geosci Remote Sens 46(2):316-327

Stewart ID (2011) A systematic review and scientific critique of methodology in modern urban heat island literature. Int J Climatol 31(2):200-217

Tran DT, Fredlund DG, Chan DH (2015) Improvements to the calculation of actual evaporation from bare soil surfaces. Can Geotech J 53(1):118-133

Tso CP (1996) A survey of urban heat island studies in two tropical cities. Atmos Environ 30(3):507-519

Tso CP, Chan BK (1990) An improvement to the basic energy balance model for urban thermal environmental analysis. Energy Build 14:143-152

Virk G, Jansz A, Mavrogianni A, Mylona A, Stocker J, Davies M (2014) The effectiveness of retrofitted green and cool roofs at reducing overheating in a naturally ventilated office in London: direct and indirect effects in current and future climates. Indoor Built Environ 23(3):504-520

Virk G, Jansz A, Mavrogianni A, Mylona A, Stocker J, Davies M (2015) Microclimatic effects of green and cool roofs in London and their impacts on energy use for a typical office building. Energy Build 88:214-228

Wang Y, Li Y, Di Sabatino S, Martilli A, Chan PW (2018) Effects of anthropogenic heat due to air-conditioning systems on an extreme high temperature event in Hong Kong. Environ Res Lett. https://doi.org/10.1088/17489326/aaa848

Yuen B, Kong L (2009) Climate change and urban planning in southeast Asia. S.A.P.I.EN.S Surv Perspect Integrating Environ Soc 2(3)

Yusuf YA, Pradhan B, Idrees MO (2014) Spatio-temporal assessment of urban heat island effects in Kuala Lumpur metropolitan city using landsat images. J Indian Soc Remote Sens 42(4):829-837

\section{Submit your manuscript to a SpringerOpen ${ }^{\odot}$ journal and benefit from:}

- Convenient online submission

- Rigorous peer review

- Open access: articles freely available online

- High visibility within the field

- Retaining the copyright to your article

Submit your next manuscript at springeropen.com 